\title{
The Use of Phosphorus-Containing Waste and Algae to Produce Biofertilizer for Tomatoes
}

\author{
Assel Tleukeyeva ${ }^{*}$, Nuradin Alibayev ${ }^{1}$, Akmaral Issayeva $^{2}$, Lyazzat Mambetova², \\ Aygul Sattarova ${ }^{3}$, Yerzhan Issayev ${ }^{1}$
}

1 M. Auezov South Kazakhstan University, Shymkent, Kazakhstan

2 Shymkent University, Shymkent, Kazakhstan

3 University of Friendship of Nations Named After Academician A. Kuatbekov, Kazakhstan

* Corresponding author's e-mail: aseltleukeyeva@mail.ru

\begin{abstract}
The current state of phosphorus-containing waste and the methods of its disposal remain relevant. The storage of phosphorus-containing waste sludge is carried out in sludge collectors, which occupy large areas. With the disposal of slags and sludge, as well as the elimination of sludge collectors, the harmful effect of waste on the soil will cease, and the possibility of using these areas for economic land use will appear. Many studies show the movement of phosphorus in soil and water, thus proving the difficulty of disposing of this waste. Of course, phosphorus slags and sludge are used in small quantities in the production of building materials, but this does not solve all the problems. In the south of Kazakhstan, there are warehouses for the waste from the production of phosphorus-containing fertilizers, which also require disposal. One of the ways of modern utilization of these wastes is their use in fertilizers for agriculture. However, since the phosphorus-containing waste has a high content of phosphorus, compared to nitrogen and potassium, this ratio can be changed with the addition of chlorella biomass. The purpose of the conducted study was to investigate the possibility of using a complex of phosphorus waste and algae, that is, the cultivation of chlorella at various concentrations of phosphorus-containing waste for further use of the suspension in watering the test plant. In the form of a test plant, tomato seeds were chosen, the cultivation of which in agriculture is economically profitable. When cultivated in closed ground, tomatoes lose their taste, which can be restored with the use of organic fertilizers. This article shows the results of the influence of various concentrations of phosphorus waste and green microalgae on the growth and development of Solanum lycopersicum.
\end{abstract}

Keywords: phosphorus-containing waste, chlorella, biofertilizers, Solanum lycopersicum, phosphorus slags, phosphorus sludge.

\section{INTRODUCTION}

Nowadays, synthetic fertilizers are often used in agriculture, including phosphorus-containing fertilizers, which are often obtained by mining from phosphorite ores. One of the largest phosphorite ores is located in Kazakhstan, which enriches the entire market of the republic. Of course, there are also side effects from such methods of obtaining fertilizers, i.e. a large amount of waste with a low content of essential elements. A small amount of this waste is used in the production of building materials, such as building blocks. However, the main problem of disposal of a large volume of phosphorus-containing waste is relevant not only for Kazakhstan, but also for the whole world.

The cultivation of agricultural crops is highly dependent on phosphorus, which is widely recognized as an important macronutrient [Zayadan, 2014]. In most cases, phosphorus fertilizers are produced from mineral rocks, economically justified reserves of which may be depleted in the coming decades [Nabors, 2000]. In this regard, it becomes necessary to introduce innovative methods of processing the phosphorus-containing waste [Madireddi, 2014]. In Switzerland, for example, the amount of phosphorus-containing waste (i.e. 
9600 tons) exceeds the annual amount of phosphorus provided by fertilizers (e.g. 4200 tons) [Marschner, 2012]. Using the example of calcium phosphite, a by-product of the production of hypophosphite and phosphine, about 300 tons of phosphorus is discharged into Switzerland every year. In terms of phosphorus reserves, Kazakhstan ranks fourth in the world. The intensive development of the phosphorus industry in the 1970-80s led to the gradual production of phosphorites with a high content of the target component (more than $28 \% \mathrm{P}_{2} \mathrm{O}_{5}$ ) and, accordingly, the accumulation of refractory ores of complex mineral raw materials and chemical composition [Childers, 2011]. The complex composition of phosphorites and close physicochemical properties of phosphate minerals and host rocks do not allow the use of known enrichment methods and obtaining concentrates of the required quality [Olivieri, 2014]. This, in turn, leads to a decrease in the quality of traditional phosphate fertilizers and the formation of a significant amount of waste. As a rule, these wastes, consisting of empty and enclosing rocks, are not utilized, but are processed into building materials, albeit in small quantities [Garni Makhan, 2017]. The ability to reuse phosphites as phosphorus fertilizers in agricultural systems can be a valuable option for optimizing the phosphorus cycle in the environment.

Chlorella suspension is a universal fertilizer that combines the properties of a biostimulant suitable for any type of plant. Its use improves the quality of the soil, accelerates the germination of seeds, strengthens the root system, helps protect against diseases and pests, as well as increases the yield of fruits and the decorative effect of flowers. Currently, this suspension is more often used for watering indoor plants. The information on the use of this fertilizer in agriculture is not significant. In addition, for the cultivation of green microalgae, various production wastes can be used; even with a minimal amount of nutrients, chlorella is able to increase biomass, purifying water during the process [Bharat, 2014]. The greatest effect from the use of such means (suspension of photosynthetic microalgae) was found when processing the seed (soaking the seeds) and using it as foliar dressing at a certain stage of plant growth (for example, for spring barley - at the stage of tillering). During pre-sowing treatment in experiments, it was proven that the seed germination energy and their germination capacity increased, as well as the size of the embryonic roots and the growth of seedlings accelerated. As a result, all this contributed to an increase in the total mass of adult plants and an increase in the biological productivity of the same barley by about 9-13.5\%. A general stimulating effect on vegetative plants was also exerted by foliar feeding (by leaves) with such preparations [Ale, 2014]. The fact is that the organic matter of such algae is an easily digestible and high-energy "product" for many soil bacteria. Thus, the algolization of soils (the introduction of algal biomass) promotes the rapid development of microbiological and biochemical processes in them, and as a result, an increase in the amount of humic acids and other valuable organic matter readily available and useful for plants.

In the modern agro-industrial complex, biotechnological ways of solving problems with organic fertilizers through the use of waste from various industries are being increasingly offered. In addition, other factors need to be considered, such as social acceptability, economic benefits and conservation of natural values. Although phosphorus is widely distributed in nature, these resources are depleted. Thus, the use of phosphate fertilizers is relevant for the whole world. The purpose of the conducted research was to obtain phosphorus-containing fertilizers with the addition of a culture of microalgae to increase the yield of agricultural crops, economically profitable and environmentally friendly, which will have import substitution [Tleukeyeva, 2021].

\section{MATERIALS AND METHODS}

The study used the microalgae isolated from the local reservoir of the city of Shymkent - the Koshkar ata river. The water samples were collected at various points in the river, such as the source of the river, the construction market area, and residential areas. The samples were cultured in Petri dishes on Myers solid nutrient medium. The cultivation of algae took place on light racks at a room temperature of $25^{\circ} \mathrm{C}$. Microscopic examination of algae was carried out on a biological and Jeol JSM-2890 scanning electron microscopes.

Myers medium for the cultivation of algae had the following composition, g.:

- $\mathrm{KNO}_{3}-1.213$

- $\mathrm{MgSO}_{4} \times 7 \mathrm{H}_{2} \mathrm{O}-1.204$

- $\mathrm{KH}_{2} \mathrm{PO}_{4}-1.224$;

- $\mathrm{Fe}_{2}\left(\mathrm{SO}_{4}\right)_{3}-0.0747$;

- agar -20 
The objects of research were phosphoruscontaining waste sludge and slags, the culture of Chlorella vulgaris ASLI-1 and tomato seeds.

The preparation of the percentage solution was carried out in accordance with GOST 4517-87. The 5\%,10\%,15\% and $20 \%$ solutions of slag and sludge were prepared, in which the chlorella strain was cultivated for a week.

Disposable plastic cups were used for sowing tomato seeds, into which $50 \mathrm{~g}$ of sterile expanded vermiculite was poured. By the sampling method, 5 tomato seeds were added to each glass, which were soaked for a day in a chlorella suspension. The top of the glasses was poured with $50 \mathrm{ml}$ of a percent solution and tightly closed with a foil.

The lengths of plants, stem and roots were measured with a ruler. The number of leaves on seedlings was counted visually.

Statistical processing of the results was performed by calculating the arithmetic mean and the standard deviation. All determinations were carried out in 3-and 5-fold repetitions. The data was processed using an IBM Pentium personal computer based on Excel application software packages.

\section{RESULTS AND DISCUSSION}

In the course of research, the chlorella strain was cultivated at various concentrations of phosphorus-containing waste solutions. After cultivating for a week, the density of chlorella cells in solutions was as follows:
- $5 \%$ solution $-7 \times 1091 / \mathrm{CFU}$;

- $10 \%$ solution $-6,7 \times 1091 / \mathrm{CFU}$;

- $15 \%$ solution $-4.2 \times 1091 / \mathrm{CFU}$;

- $20 \%$ solution $-2.3 \times 1091 / \mathrm{CFU}$.

According to these data, it can be noted that a high concentration of phosphorus-containing wastes is a limiting factor for the culture of Chlorella vulgaris ASLI-1.

Despite the fact that the chemical composition of sludge and slag is similar, their effect on growth and development was different. In addition, a $20 \%$ solution of phosphorus-containing waste sludge has a detrimental effect on the test plant.

During the study, it was found that the germination and development of test plants were better in the samples with the addition of a suspension of chlorella, which is in a solution only with the content of phosphorus-containing waste (Figure 1).

As shown in the diagram at a $5 \%$ solution of slags and sludge, especially when adding a suspension of microalgae, the germination rate was $100 \%$. It is also worth noting that there is no germination at $15 \%$ and $20 \%$ sludge solution, but when chlorella suspension was added, the germination rate was $10 \%$ and $20 \%$, respectively. Moreover, one can see the regularity that when the suspension is added to the solutions for watering seeds, germination improves. Seed mold is also reduced.

When measuring the length of roots and stems, it was noted that the solutions with slag content have a greater effect on the length of the roots, and the solutions with sludge content have

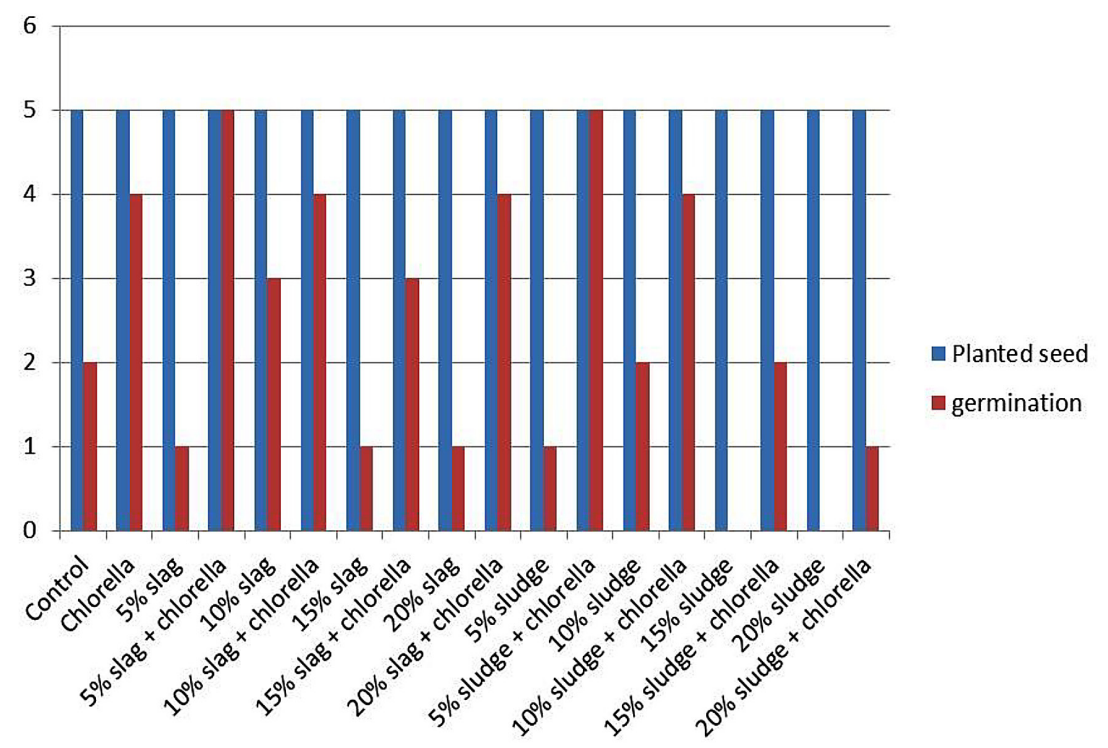

Figure 1. Seed germination of a test plant at various concentrations of fertilizers 


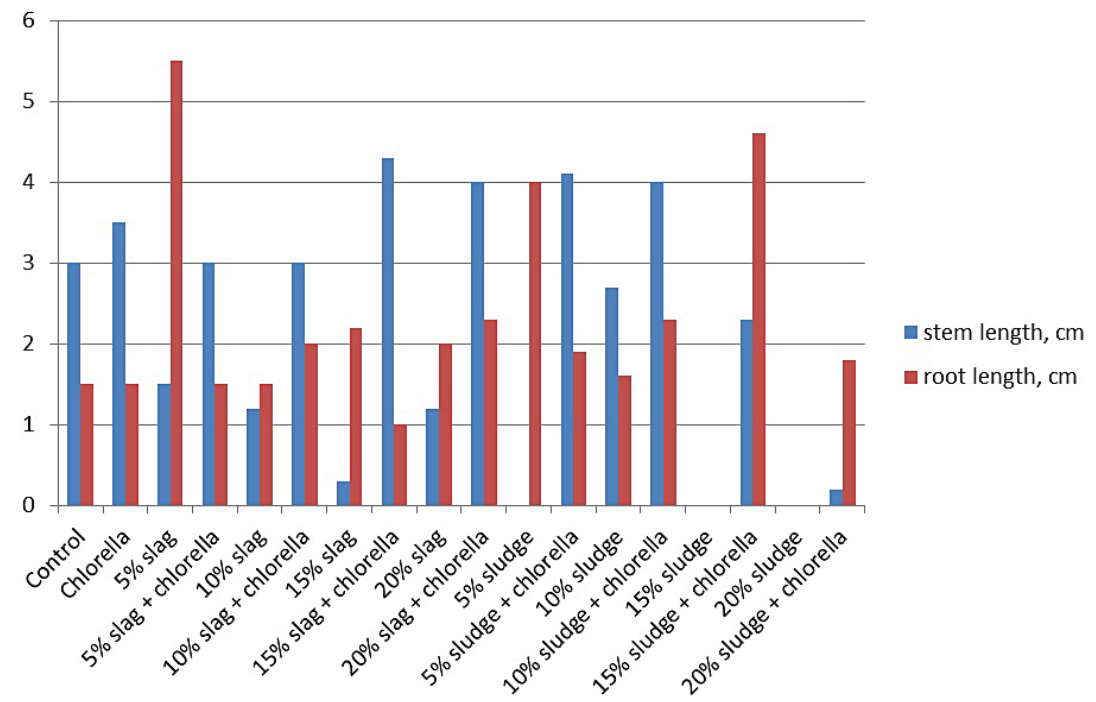

Figure 2. Influence of different solutions on the length of the stem and roots of the test plant

a more pronounced effect on accelerating the growth of stems (Figure 2).

As can be seen in the figure, the slag solutions with microalgae have a positive effect on the development of tomato seeds. Compared to the control variant with pure water and chlorella, the test samples showed better results, except for the sample with a $20 \%$ sludge solution. In the sample with $5 \%$ slag solution, the stem length exceeded the stem length by 5 times in the control variant, and in the sample with $15 \%$ slag solution with the addition of chlorella culture, the stem length exceeded the stem length in the control 1.5 times. With regard to sludge, $15 \%$ and $20 \%$ solutions turned out to be fatal for the test plant, but when chlorella culture was added, several seeds germinated, the root length of which averaged $2.1 \mathrm{~cm}$.

It was also noted that the cups in which there were solutions with a suspension of chlorella were less moldy and retained moisture longer, which is undoubtedly a good indicator for using the culture of microalgae in fertilizers.

\section{CONCLUSIONS}

Thus, according to the results of the study, it is possible to note a positive dynamics of the tomato seeds germination when using a complex solution of phosphorus-containing wastes and a culture of chlorella. Thus, it was found that a $20 \%$ slime solution is detrimental to chlorella cells and test plant seeds, the optimal concentration for plant growth is a $5 \%$ slag solution with the addition of a chlorella culture, where germination was $100 \%$, and the root length averaged $5.5 \mathrm{~cm}$, the length of the stem is on average $3 \mathrm{~cm}$. Upon visual observation, tomato sprouts were stronger and more developed in the variant of the phosphorus containing slag and Chlorella vulgaris ASLI-1 complex. The work in this direction will be continued on other types of agricultural plants.

\section{REFERENCES}

1. Ale M.T., Pinelo M., Meyer A.S. 2014. Assessing effects and interactions among key variables affecting the growth of mixotrophic microalgae: ph, inoculum volume, and growth medium composition. Preparative Biochemistry and Biotechnology, 44, 242-256.

2. Bharat G., Patel J.P., Kothari I.L. 2014. Cultivation of Chlorella protothecoides (ISIBES-101) under autotrophic and heterotrophic conditions for biofuel production. J. Algal Biomass Utilization, 5(2), 20-29.

3. Childers D.L., Corman J., Edwards M., Elser J.J. 2011. Sustainability challenges of phosphorus and food: solutions from closing the human phosphorus cycle. Bioscience, 61(2011), 117-124.

4. Garni Makhan A.Z., Anarbekova A.I., Abildaeva R.A., Dauilbai A.D., Rysbayeva G.S. 2017. Cyanobacteria Spirulina: biological characteristics and the role in biotechnology, Reports of the Academy of sciences of the republic of Kazakhstan Satbayev university. Series of geology and technical sciences, 1, http://doi.org/10.32014/2020.2518-1483.000

5. Madireddi N., Daniel D.K., Sankar V., Krastanov A. 2012. Effect of dioxide on the rheological behavior of submerged cultures of Chlorella minutissima in stirred tank reactors. Eng. Life Sci., 5, 529-533. 
6. Marschner H. 2012. Marschner's Mineral Nutrition of Higher Plants, 89.

7. Nabors, Murray W. 2000. Introduction to Botany. San Francisco, CA. Pearson Education, Inc.

8. Olivieri G., Salatino P., Marzocchella A. 2014. Advances in photobioreactors for intensive microalgal production: configurations, operating strategies and applications J. Chem. Technol. Biotechnol., 89.

9. Tleukeyeva A.E., Pankiewicz R., Alibayev N., Issayeva A.U. 2021. The possibility of using green algae as fertilizer in agriculture, Reports of the National Academy of Sciences of the
Republic of Kazakhstan, 1(335), 19-23. http://doi. org/10.32014/2021.2518-1483.3

10. Tleukeyeva A.E., Pankiewicz R., Alibayev N., Issayeva A.U., Tleukeyev Zh. 2021. Green Algae as a Way to Utilize Phosphorus Waste. Journal of Ecological Engineering, 22(10), 235-240. http:// doi.org/10.12911/22998993/142451

11. Zayadan B.K., Purton S., Sadvakasova A.K., Userbaeva A.A., Bolatkhan K. 2014. Isolation, mutagenesis and optimization of cultivation conditions for microalgae strains for the production of biodiesel. Plant Physiology, 61(1), 135-142. 